\title{
Crescimento, nutrição e produção da bananeira associados a plantas de cobertura e lâminas de irrigação
}

\author{
Francisca E. L. Barbosa', Claudivan F. de Lacerda', Hernandes de O. Feitosa', \\ Ismail Soares ${ }^{2}$, Francisco L. de Andrade Filho' \& Aiala V. Amorim ${ }^{3}$
}

\begin{abstract}
RESUMO
Com este trabalho objetivou-se avaliar o crescimento, a nutrição e a produção da bananeira Prata Anã (Musa spp), consorciada com leguminosas e submetida a diferentes lâminas de irrigação. O delineamento experimental utilizado foi em blocos casualizados em parcelas subdivididas, com cinco repetições. As parcelas foram formadas por quatro lâminas de irrigação: 50, 75, 100 e 125\% da evapotranspiração da cultura (ETC) e as subparcelas pela testemunha (manejo convencional sem plantas de cobertura) e três tipos de plantas de cobertura consorciadas com a bananeira, são elas: vegetação espontânea (VE), cudzu tropical em sucessão à crotalária (CK) e calopogônio em sucessão ao feijão-de-porco (FC). Avaliaram-se, nas plantas de bananeira, a altura, a circunferência do pseudocaule, os teores foliares de macro e micronutrientes, a produção e a duração do ciclo. A utilização de leguminosas no pré-plantio e como cobertura viva, exerceu influências positivas no crescimento, na nutrição nitrogenada e na produção da bananeira, substituindo parcialmente o $\mathrm{N}$ aplicado como fertilizante mineral. $\mathrm{O}$ uso de leguminosas consorciadas com a bananeira representa uma alternativa adequada para o fornecimento de $\mathrm{N}$ à cultura da bananeira.
\end{abstract}

Palavras-chave: manejo da irrigação, adubação verde, Musa spp.

\section{Growth, nutrition and yield of banana associated with cover crops and irrigation depths}

\begin{abstract}
The objective of this study was to evaluate the growth, nutrition and production of Prata Anã banana (Musa spp), intercropped with legumes and subjected to different irrigation depths. The experimental design was a randomized block split plot with five replications. The plots were formed by four irrigation depths: 50, 75,100 and $125 \%$ of crop evapotranspiration (ETC) and the control subplots (conventional management without cover crops) and three types of cover crops intercropped with banana: spontaneous vegetation (VE), tropical cudzu in succession to crotalaria (CK) and calopogônio in succession to jack beans (FC). In banana crop, the height, pseudostem circumference, foliar concentrations of macro and micronutrients, production and crop cycle duration were evaluated. The use of legumes in the pre-planting and as a cover crop exerted positive influences on growth, nitrogen nutrition and yield of banana, partially replacing the $\mathrm{N}$ applied as mineral fertilizer. The use of legumes intercropped with banana represents an adequate alternative to provide $\mathrm{N}$ for banana.
\end{abstract}

Key words: irrigation management, green manure, Musa spp. 


\section{INTRODUÇÃO}

A banana é uma fruta mundialmente consumida e uma das mais exploradas no mundo. Segundo a FAO (2012) sua produção mundial foi, em 2009, de 95,6 milhões de megagramas (Mg), o que a qualifica como a segunda fruta mais produzida no mundo, superada apenas pela melancia, com 99,2 milhões de Mg.

A exploração da bananeira em condições irrigadas tem sido proposta principalmente para os locais em que as precipitações não são suficientes para suprir as necessidades hídricas da cultura. Esta técnica reduz o ciclo da bananeira (Figueiredo et al., 2006) e favorece aumentos de produtividade (Coelho et al., 2006; Costa et al., 2009) o que é fato relevante sob a ótica da expansão da bananicultura irrigada em regiões semiáridas.

Além do suprimento adequado de água, exigências nutricionais elevadas têm sido relatadas para a bananeira, com destaque principalmente para o potássio e o nitrogênio. Para o $\mathrm{N}$, as quantidades recomendadas variam de $352 \mathrm{~kg} \mathrm{ha}^{-1} \mathrm{ano}^{-1}$ (Santos et al., 2009) até $1050 \mathrm{~kg} \mathrm{ha}^{-1}$ ano $^{-1}$ (Melo et al., 2010). As elevadas adubações com fertilizantes nitrogenados implicam em aumento dos custos de produção e também potencializam os riscos de contaminação das águas do lençol freático pela lixiviação de nitrato, principalmente quando são realizadas irrigações além das exigências das culturas ou mesmo após a ocorrência de elevadas precipitações (Zhu et al., 2005).

Uma alternativa à redução do uso de fertilizantes nitrogenados é sua substituição por leguminosas conduzidas como adubo verde ou na forma de consórcio. Essas plantas incrementam o $\mathrm{N}$ e a matéria orgânica do solo contribuindo diretamente para a qualidade do mesmo (Silva et al., 2007); também promovem mobilização e reciclagem de nutrientes, protegem o solo contra a erosão hídrica e eólica e variações térmicas das camadas superficiais do solo reduzindo as perdas de água por evaporação e se mostrando importantes para a conservação do solo.

No caso do consórcio com fruteiras as leguminosas herbáceas perenes se mostram bastante promissoras (Bremer Neto et al., 2008) pelo fato de serem mantidas como coberturas vivas por meio de roçadas periódicas, após semeio, dispensando nova compra de sementes ou mudas em ciclos posteriores da cultura principal. Para a bananeira resultados de pesquisas têm demonstrado boa eficiência das plantas de cobertura no que diz respeito ao fornecimento do N (Espíndola et al., 2006b; Perin et al., 2009) mas muito ainda se precisa saber sobremaneira no que diz respeito à escolha das melhores plantas de cobertura e do manejo desse sistema sob irrigação em regiões semiáridas.

Neste contexto objetivou-se avaliar o crescimento, a nutrição e a produção da bananeira cv Prata Anã consorciada com leguminosas como plantas de cobertura e submetidas a diferentes lâminas de irrigação.

\section{Material e Métodos}

A pesquisa foi conduzida entre setembro de 2010 e novembro de 2011, na Fazenda Experimental do Vale do Curu, pertencente à Universidade Federal do Ceará, localizada no município de Pentecoste - CE, distante $100 \mathrm{~km}$ da capital do estado, Fortaleza, CE, com as coordenadas $3^{\circ} 48^{\prime}$ de latitude
Sul e $39^{\circ} 19^{\prime}$ de longitude Oeste, com altitude de $47 \mathrm{~m}$. O clima da região, de acordo com a classificação de Koppen, é do tipo BSw'h', semiárido com chuvas irregulares, com precipitação pluvial média anual de $801 \mathrm{~mm}$ e período crítico de deficiência hídrica estendendo-se de junho a janeiro.

O solo da área experimental é classificado como Neossolo Flúvico (EMBRAPA, 1997) e apresenta as seguintes características químicas: $\mathrm{pH}$ (água) $=7,1 ; \mathrm{CE}=$ $0,36 \mathrm{dS} \mathrm{m}^{-1} ; 0,75 \mathrm{~g} \mathrm{~kg}^{-1}$ de N; $24 \mathrm{mg} \mathrm{kg}^{-1}$ de P; 13,3 $\mathrm{g} \mathrm{kg}^{-1}$ de M.O.; 12,95 $\mathrm{cmol}_{\mathrm{c}} \mathrm{kg}^{-1}$ de CTC; $92 \%$ de V; e 9,1; 2,2; 0,$27 ; 0,99 ; 0,05 ; 0,38 \mathrm{cmol}_{\mathrm{c}} \mathrm{kg}^{-1} \mathrm{de} \mathrm{Ca}^{2+}, \mathrm{Mg}^{2+}, \mathrm{K}^{+}, \mathrm{H}^{+}+$ $\mathrm{Al}^{3+}, \mathrm{Al}^{3+} \mathrm{e} \mathrm{Na}^{+}$, respectivamente.

O delineamento experimental utilizado foi em blocos casualizados em parcelas subdivididas, com cinco repetições. As parcelas foram formadas por quatro lâminas de irrigação, $50,75,100$ e $125 \%$ da evapotranspiração da cultura (ETc) e as subparcelas pela testemunha (manejo convencional da adubação nitrogenada sem plantas de cobertura) e três tipos de plantas de cobertura consorciadas com a bananeira, são elas: vegetação espontânea (VE), cudzu tropical (Pueraria phaseoloides) em sucessão à crotalária (Crotalária juncea) $(\mathrm{CK})$ e calopogônio (Calopogonium muconoides $\mathrm{L}$ ) em sucessão ao feijão-de-porco (Canavalia ensiformes) (FC).

As parcelas $(12 \times 40 \mathrm{~m})$ foram compostas de quatro fileiras de bananeira cv Prata Anã, plantadas em sistema de fileiras simples com espaçamento de $3 \times 2 \mathrm{~m}$, sendo constituídas de 80 plantas. As subparcelas tinham dimensões de $12 \times 10 \mathrm{~m}$, com vinte plantas, sendo as seis plantas centrais utilizadas nas avaliações totalizando oitenta unidades experimentais.

As leguminosas crotalária e feijão-de-porco foram conduzidas antes do transplantio da bananeira. As sementes foram distribuídas em quatro fileiras espaçadas $0,50 \mathrm{~m}$ e localizadas nas entrelinhas nas quais foram transplantadas, posteriormente, as bananeiras. A densidade de plantio utilizada foi de 27 e 5 sementes por metro linear para a crotalária e feijãode-porco, respectivamente. A irrigação foi realizada diariamente repondo o total evapotranspirado; aos 55 dias após plantio (DAP) as plantas foram cortadas a $0,10 \mathrm{~m}$ do solo e deixadas como cobertura morta.

As leguminosas perenes cudzu tropical e calopogônio foram plantadas um mês após o transplantio das bananeiras e foram distribuídas em sete fileiras espaçadas $0,25 \mathrm{~m}$ e localizadas nas entrelinhas da bananeira na forma de consórcio, sendo manejadas como coberturas vivas por meio de cortes (roço) aos 105 e 200 dias após o plantio (DAP). Na área com plantas espontâneas foram encontradas espécies de leguminosas e gramíneas tais como: Desmanthus virgatus (L) Willd e Rhynchosia minima (L) DC, sendo o predomínio da gramínea Panicum máximum Jack. A vegetação espontânea também foi mantida como cobertura viva por meio dos cortes realizados aos $105,150,200$ e 300 DAP.

O transplantio das mudas micropropagadas da bananeira foi realizado no início de novembro de 2010, imediatamente após o corte das leguminosas anuais. Nas covas com dimensões de $40 \times 40 \mathrm{~cm}$, foram adicionados $10 \mathrm{~L}$ de esterco bovino curtido; $50 \mathrm{~g}$ de calcário dolomítico; $15 \mathrm{~g}$ de FTEBR $12 \mathrm{e}$ NPK na forma de ureia, superfosfato simples e cloreto de potássio. A aplicação de adubo nitrogenado (ureia) correspondeu a $700 \mathrm{~kg} \mathrm{ha}^{-1} \mathrm{ano}^{-1}$ 
para a testemunha aplicados aos $0,65,155$ e 240 dias após o transplantio (DAT) e apenas $32 \mathrm{~kg} \mathrm{ha}^{-1} \mathrm{ano}^{-1}$ para os demais tratamentos, aplicados no transplantio. O P $\left(90 \mathrm{~kg} \mathrm{ha}^{-1} \mathrm{ano}^{-1} \mathrm{de}\right.$ $\mathrm{P}_{2} \mathrm{O}_{5}$ ) foi adicionado em uma única aplicação por ocasião do transplantio enquanto as quantidades de K (462 kg ha-1 ano $\mathrm{kg}^{-1}$ de $\mathrm{K}_{2} \mathrm{O}$ ) foram parceladas em quatro vezes, igualmente ao nitrogênio da testemunha.

Para a estimativa das lâminas de irrigação foi utilizado o valor diário da evapotranspiração de referência $\left(\mathrm{ET}_{0}\right)$ obtida com base no monitoramento climático do tanque classe A e pelo coeficiente da cultura (Kc) obtidos por Silva \& Bezerra (2009). O manejo das lâminas de irrigação nas parcelas foi iniciado aos 54 DAT e interrompido aos 71 DAT devido ao início das chuvas, o que impossibilitou a diferenciação das lâminas. A retomada desse manejo ocorreu aos 245 DAT, período de intensa frutificação da bananeira permanecendo até o final do $1^{\circ}$ ciclo. As lâminas de irrigação aplicadas nos dois períodos foram: L1 $=390,7 \mathrm{~mm}$; L2 = 586,1 mm; L3 = 781,5 mm; e L4 = 976,9 mm. No entanto, em função do elevado total de precipitação no ano de 2011 (1095,9 mm) as lâminas totais no primeiro ciclo foram bem superiores $(\mathrm{L} 1=1486,6 \mathrm{~mm}$; L2 = 1682,0 mm; L3 $=1877,4 \mathrm{~mm}$; e L4 = 2072,8 mm).

A altura das plantas, medida do solo até a roseta foliar e a circunferência do pseudocaule medidana base da planta junto ao solo foram realizadas aos 90, 140, 195 e 245 dias após o transplantio (DAT) com auxílio de uma fita métrica.

Amostras foliares de seis plantas úteis de cada subparcela foram coletadas no período em que se iniciou a emissão da inflorescência sendo retirada, para análise, a parte interna mediana do limbo da $3^{\mathrm{a}}$ folha a contar do ápice selecionandose de 10 a $15 \mathrm{~cm}$ e se eliminando a nervura central (Malavolta et al., 1997). Nos materiais secos e moídos foram realizadas as extrações e determinação de N, P, K, Ca, Mn, Cu, Fe e Zn, conforme metodologia descrita por Malavolta et al. (1997).

A colheita dos frutos foi iniciada aos 10 meses após o transplantio (setembro de 2011) e se estendeu até o início de dezembro com frutos colhidos no estádio de maturação I (fruto fisiologicamente maduro mas com casca totalmente verde) de acordo com a escala de graus de coloração da casca; nela foram selecionados os cachos das plantas úteis de cada subparcela e determinados: peso do cacho com engaço, peso do cacho sem engaço, número de frutos por cacho, número de frutos por penca e calculada a produtividade a partir do produto do peso do cacho sem engaço das plantas úteis (valor médio) e a densidade de plantio. A duração do ciclo foi determinada com base na média das datas de colheita das plantas úteis de cada tratamento.

Os dados de cada característica avaliada foram submetidos à análise de variância e posteriormente, quando significativos pelo teste $\mathrm{F}$, foram submetidos ao teste de médias de Tukey com $\mathrm{p}<0,05$ (comparação dos tratamentos nas subparcelas) e à análise de regressão (efeitos das lâminas de irrigação). $\mathrm{Na}$ análise de regressão as equações que melhor se ajustaram aos dados foram selecionadas com base na significância dos coeficientes de regressão a 0,01 e 0,05 de probabilidade pelo teste $\mathrm{F}$ e com maior coeficiente de determinação.

\section{Resultados E Discussão}

A ANOVA revelou que as lâminas de irrigação não influenciaram as variáveis de crescimento nem os componentes de produção da bananeira $(\mathrm{P}>0,05)$ tendo causado efeitos significativos apenas para os teores foliares de $\mathrm{N}(\mathrm{P}<0,01) \mathrm{e}$ $\mathrm{Mn}(\mathrm{P}<0,05)$. A pequena influência das lâminas de irrigação se deve, em grande parte, às elevadas precipitações ocorridas durante o primeiro ciclo da bananeira, de modo que a menor lâmina aplicada atingiu valor considerado adequado para atender à demanda da cultura (Figueiredo et al., 2006). De forma contrária, as plantas de cobertura causaram efeitos significativos sobre todas as variáveis de crescimento e de produção $(\mathrm{P}<0,01)$ e também influenciaram os teores de $\mathrm{N}$ $(\mathrm{P}<0,01), \mathrm{Zn}(\mathrm{P}<0,01), \mathrm{Fe}(\mathrm{P}<0,05)$ e $\mathrm{Mn}(\mathrm{P}<0,01)$. Para as variáveis analisadas não foram verificadas interações entre os fatores testados.

Comparando o efeito dos diferentes consórcios na altura das plantas (Figura 1A), observou-se que aos 90 DAT as plantas consorciadas com leguminosas possuíam alturas significativamente superiores em comparação à testemunha e ao consórcio com a vegetação espontânea. Nas avaliações seguintes a altura das plantas na testemunha superou as plantas consorciadas com as leguminosas enquanto as plantas

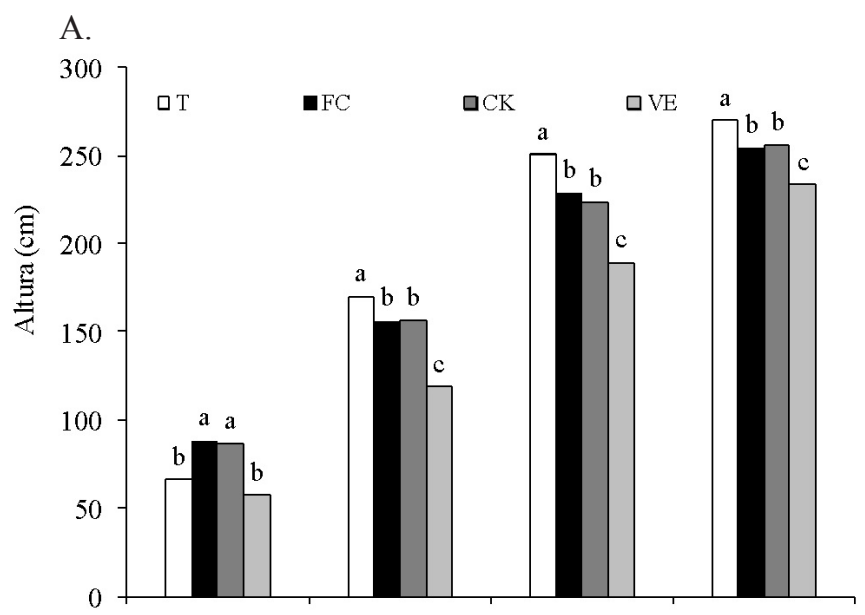

B.

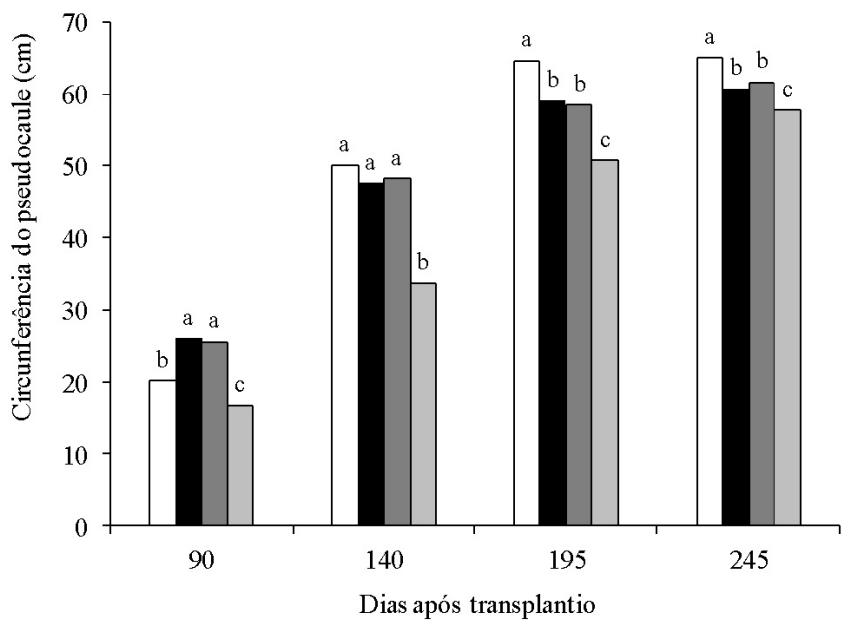

T- testemunha, manejo convencional sem plantas de cobertura, FC- calopogônio em sucessão ao feijão-de-porco, CK- cudzu tropical em sucessão a crotalária, VE- vegetação espontânea.

Médias seguidas pelas mesmas letras iguais não diferem entre si pelo teste de Tukey, a 0,05 de probabilidade

Figura 1. Valores médios da altura (A) e circunferência do pseudocaule (B) da bananeira cv Prata Anã em função dos tratamentos com plantas de cobertura 
consorciadas com a vegetação espontânea apresentaram alturas significativamente menores que as demais.

Os dados da circunferência do pseudocaule das bananeiras (Figura 1B) apresentaram a mesma tendência dos dados da altura (Figura 1A) com exceção da avaliação realizada aos 140 DAT, quando a circunferência das plantas na testemunha não diferiu das plantas consorciadas com as leguminosas.

Os maiores valores da altura e da circunferência do pseudocaule observadas nas bananeiras consorciadas com as leguminosas aos 90 DAT se devem, provavelmente, à maior disponibilidade do $\mathrm{N}$ proveniente da mineralização da parte aérea das leguminosas anuais, feijão-de-porco e crotalária, cultivadas no pré-plantio das bananeiras, haja vista que a adubação de fundação consistiu de $32 \mathrm{~kg} \mathrm{ha}^{-1}$ de ureia para todos os tratamentos. Dados semelhantes aos obtidos no presente trabalho foram verificados por Pereira (2009) na bananeira cv. Pacovan conduzida em áreas com pré-plantio das leguminosas crotalária e feijão-de-porco. $\mathrm{O}$ efeito positivo do pré-cultivo com leguminosas também foi observado em culturas anuais como milho (Spagnollo et al., 2002), berinjela (Castro et al., 2004) e algodoeiro (Carvalho et al., 2004).

Os maiores valores de altura das bananeiras testemunha a partir dos 140 DAT e da circunferência do pseudocaule a partir dos 195 DAT, foram influenciados pelas adubações nitrogenadas de cobertura que proporcionaram aumento do $\mathrm{N}$ disponível no solo. No mesmo período a disponibilidade do $\mathrm{N}$ nas áreas com consórcio de leguminosas foi reduzida devido à rápida mineralização do $\mathrm{N}$ do tecido da crotalária $\mathrm{e}$ feijão-de-porco. Esta rápida mineralização está relacionada à baixa relação $\mathrm{C} / \mathrm{N}$ das leguminosas que reduz o tempo de mineralização do $\mathrm{N}$ do tecido dessas plantas (Espindola et al., 2006a) sendo geralmente responsável por rendimentos inferiores em sistemas com uso de leguminosas em comparação ao manejo com fornecimento de $\mathrm{N}$ na forma de fertilizante mineral (Kramberger et al., 2009). Por outro lado, a menor altura da planta e circunferência do pseudocaule das bananeiras consorciadas com a vegetação espontânea podem estar associadas à menor disponibilidade de $\mathrm{N}$ ocasionada pela imobilização desse nutriente pelos micro-organismos do solo e pela adição das gramíneas com maior relação $\mathrm{C} / \mathrm{N}$ (Espindola et al., 2006a).

$\mathrm{O}$ maior teor de $\mathrm{N}$ foi observado nas bananeiras da testemunha seguido das plantas sob os consórcios FC e CK, sendo os menores teores deste elemento observados nas bananeiras consorciadas com a vegetação espontânea (Tabela 1). Dentre os micronutrientes o $\mathrm{Zn}$ apresentou menores teores nas bananeiras da testemunha e o inverso ocorreu com o $\mathrm{Mn}$ cujos teores atingiram $527 \mathrm{mg} \mathrm{kg}^{-1}$ neste tratamento; nas plantas consorciadas com a vegetação espontânea o teor de $\mathrm{Fe}$ das folhas foi significativamente maior que nos demais tratamentos (Tabela 1).

No presente trabalho os resultados encontrados para os teores de $\mathrm{N}$ estão abaixo da faixa correspondente a $27-36 \mathrm{~g} \mathrm{~kg}^{-1}$ considerada ideal por Malavolta et al. (1997) e também dos 25-29 $\mathrm{g} \mathrm{kg}^{-1}$ sugeridos por Silva et al. (2002) para bananeira Prata-Anã; no caso das plantas sob consórcio, também foram encontrados teores de $\mathrm{N}$ inferiores aos observados por Espindola
Tabela 1. Teores foliares de N, Zn, Fe e Mn da bananeira cv Prata Anã em função dos tratamentos com plantas de cobertura

\begin{tabular}{ccccc}
\hline Tratamento & $\mathbf{N}$ & \multicolumn{1}{c}{$\mathbf{Z n}$} & $\mathbf{F e}$ & $\mathbf{M n}$ \\
\cline { 3 - 5 } & $\left.\mathbf{( g ~ k g}^{-1}\right)$ & & $\left(\mathbf{m g ~ k g}^{-1}\right)$ & \\
T & $24,71 \mathrm{a}^{1}$ & $20,99 \mathrm{~b}$ & $84,64 \mathrm{~b}$ & $526,95 \mathrm{a}$ \\
FC & $21,46 \mathrm{~b}$ & $31,24 \mathrm{ab}$ & $96,74 \mathrm{~b}$ & $208,41 \mathrm{~b}$ \\
CK & $19,76 \mathrm{bc}$ & $32,58 \mathrm{a}$ & $90,61 \mathrm{~b}$ & $177,13 \mathrm{~b}$ \\
VE & $18,31 \mathrm{c}$ & $24,52 \mathrm{ab}$ & $194,76 \mathrm{a}$ & $185,66 \mathrm{~b}$ \\
\hline
\end{tabular}

T - Testemunha, manejo convencional sem plantas de cobertura, FC - Calopogônio em sucessão ao feijão-de-porco, CK - Cudzu tropical em sucessão a crotalária, VE - Vegetação espontânea

${ }^{1}$ Médias seguidas da mesma letra na coluna não diferem entre si pelo teste de Tukey, a 0,05 de probabilidade

et al. (2006b) num consórcio da bananeira cv Nanicão com leguminosas herbáceas perenes e vegetação espontânea composta por capim colonião, fato passível de estar relacionado, pelo menos em parte, ao baixo teor inicial deste nutriente no solo (0,75 $\left.\mathrm{g} \mathrm{kg}^{-1}\right)$ visto que Malavolta et al. (1997) sugerem que teores no solo inferiores a $0,8 \mathrm{~g} \mathrm{~kg}^{-1}$ são muito baixos.

Os maiores teores de $\mathrm{Zn}$ das bananeiras em consórcio (Tabela 1) podem ser atribuídos aos efeitos dos resíduos das leguminosas e à vegetação espontânea, que tenham influenciado positivamente a quantidade e a disponibilidade deste elemento no solo. Fernandes (2006) afirma que a presença do Zn nos horizontes superficiais do solo é dependente da liberação deste nutriente dos resíduos de plantas depositados na superfície e de sua capacidade de fixação à matéria orgânica e a alguns coloides do solo.

Os teores significativamente maiores do Fe nas plantas de bananeira consorciadas com a vegetação espontânea (Tabela 1) podem ser resultado do maior teor deste nutriente nos resíduos das gramíneas que compunham a vegetação espontânea e do maior aporte total de massa seca no referido tratamento (dados não mostrados). Plantas da família das gramíneas geralmente são mais eficientes na absorção de Fe em comparação a outras espécies de plantas pois a absorção ocorre via sideróforos (quelato) sem redução e independentemente do $\mathrm{pH}$ do solo (Prado, 2008). Kabaija \& Smith (1988) verificaram que os teores de Fe de 315 e $301 \mathrm{mg} \mathrm{kg}^{-1}$ encontrados nas graminhas capim guiné e capim gigante foram significativamente maiores que

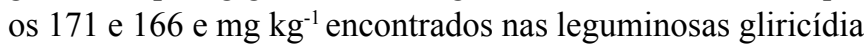
e leucena, respectivamente.

Teores significativamente superiores de $\mathrm{Mn}$ foram observados nas plantas testemunha (Tabela 1) e podem ter sido influenciados, em parte, pelo antagonismo do Mn com o Fe e pelo maior teor de $\mathrm{N}$ das plantas desse tratamento. A interação antagônica entre Mn e Fe é bem conhecida e pode ser explicada pela inibição da absorção e até mesmo do transporte de $\mathrm{Mn}$ quando da presença do $\mathrm{Fe}$ e outros cátions como $\mathrm{Ca}$, $\mathrm{Zn}$ e Mg; a semelhança do raio iônico entre esses elementos pode favorecer a absorção de um deles em detrimento do $\mathrm{Mn}$; no entanto, o contrário também é verdadeiro principalmente para o Fe (Prado, 2008).

Resende et al. (2010) observaram incrementos no teor de Mn da parte aérea da alface com o aumento de doses de $\mathrm{N}$ no solo. A maior disponibilidade de Mn nas subparcelas testemunhas também pode ser resultado da redução do $\mathrm{pH}$ do solo pela 
adição da ureia, haja vista que a redução do $\mathrm{pH}$ pode elevar a disponibilidade desse micronutriente (Prado, 2008).

O aumento das lâminas de irrigação provocou decréscimo linear nos teores foliares de $\mathrm{N}$ e Mn (Figura 2). No caso do $\mathrm{N}$ (Figura 2A) pode ter ocorrido lixiviação de $\mathrm{N}$ nítrico para além do alcance do sistema radicular da bananeira. Esta lixiviação pode ter sido intensificada também pelo elevado total de precipitação, que resultou numa lâmina de 2078,2 mm no tratamento com $125 \%$ da ETc. Em um estudo de campo durante dois anos, Zhu et al. (2005) identificaram o aumento da lixiviação de nitrato com o aumento do volume de água aplicada ao solo e afirmam que irrigações além das exigências das culturas e chuvas fortes afetaram a drenagem profunda e lixiviação de nitrato de um Cambissolo na planície norte da China. No caso do Mn (Figura 2B) a lixiviação é pouco provável devido à sua presença na forma de cátions, no solo (Prado, 2008) o que faz crer que o decréscimo de seu teor nas folhas da bananeira com o aumento da lâmina pode estar associado à redução nos teores de $\mathrm{N}$.
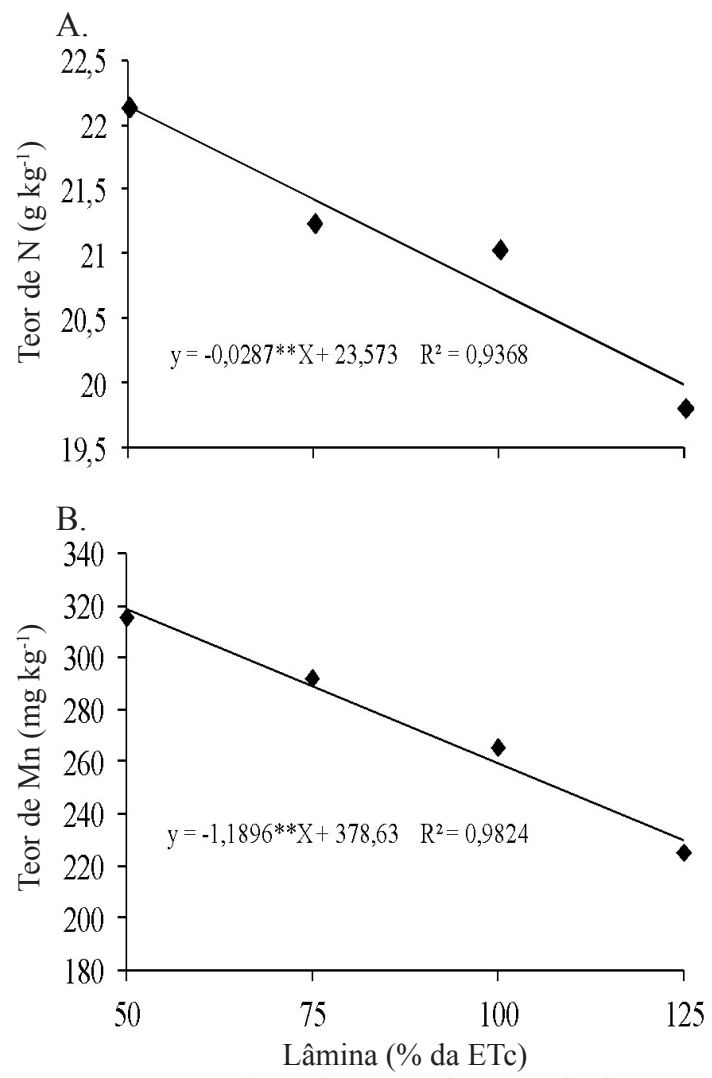

Figura 2. Teor foliar de $\mathrm{N}$ e de $\mathrm{Mn}$ da bananeira cV Prata Anã em função das lâminas de irrigação correspondentes a 50,75, 100 e $125 \%$ da evapotranspiração da cultura (ETc)

Os resultados referentes à produção da bananeira Prata Anã no primeiro ciclo de cultivo (Tabela 2) evidenciam o efeito do consórcio em todas as variáveis analisadas. De maneira geral, os maiores valores dos componentes de produção foram observados na testemunha com as plantas consorciadas com leguminosas alcançando valores mais elevados em comparação às plantas consorciadas com a vegetação espontânea. Apenas no peso do cacho sem engaço e na produtividade não foi observada diferença
Tabela 2. Peso do cacho com engaço (PCCE); peso do cacho sem engaço (PCSE); número de pencas (NP); número de frutos por cacho (NFC); número de frutos por penca (NFP); produtividade (PRT) e duração do ciclo (DC) da bananeira cv Prata Anã em função dos tratamentos com plantas em cobertura

\begin{tabular}{|c|c|c|c|c|c|c|c|}
\hline \multirow{2}{*}{ Tratamento } & PCCE & PCSE & \multirow{2}{*}{ NP } & \multirow{2}{*}{ NFC } & \multirow{2}{*}{ NFP } & \multirow{2}{*}{$\begin{array}{c}\text { PRT } \\
\left(\mathrm{Mg} \mathrm{ha}^{-1}\right)\end{array}$} & \multirow{2}{*}{$\begin{array}{c}\mathrm{DC} \\
\text { (dias) }\end{array}$} \\
\hline & \multicolumn{2}{|c|}{ (kg) } & & & & & \\
\hline $\mathrm{T}$ & $18,18 a^{1}$ & $17,61 \mathrm{a}$ & $9 \mathrm{a}$ & $139 a$ & $15 \mathrm{a}$ & $29,34 \mathrm{a}$ & $334 \mathrm{a}$ \\
\hline $\mathrm{FC}$ & $15,71 b$ & 13,86 b & $8 \mathrm{~b}$ & $108 \mathrm{~b}$ & $14 \mathrm{~b}$ & $24,00 \mathrm{~b}$ & $341 \mathrm{~b}$ \\
\hline CK & $15,31 \mathrm{~b}$ & $13,67 \mathrm{bc}$ & $8 b$ & $108 \mathrm{~b}$ & $14 \mathrm{~b}$ & 22,78 bc & $342 \mathrm{~b}$ \\
\hline VE & $12,97 \mathrm{c}$ & $12,51 \mathrm{c}$ & $7 \mathrm{c}$ & $93 \mathrm{C}$ & $13 c$ & $20,84 \mathrm{c}$ & $374 \mathrm{c}$ \\
\hline
\end{tabular}

T - Testemunha, manejo convencional sem plantas de cobertura, FC - Calopogônio em sucessão ao feijão-de-porco, CK - Cudzu tropical em sucessão à crotalária, VE - Vegetação espontânea.

${ }^{1}$ Médias seguidas da mesma letra na coluna não diferem entre si pelo teste de Tukey, a 0,05 de probabilidade

significativa entre as plantas sob o consórcio com $\mathrm{CK}$, em comparação ao consórcio VE, apesar dos maiores valores desses componentes terem sido observados nas áreas com as leguminosas.

Em estudo semelhante, Espindola et al. (2006b) verificaram que o consórcio do cudzu tropical com a bananeira, cultivar Nanicão (subgrupo Cavendish) proporcionou aumentos na produtividade, na massa total do cacho, massa total das pencas, no número de frutos por cacho e de pencas por cacho, em relação ao consórcio com a vegetação espontânea associado ao uso da adubação com ureia. Contrariamente ao observado no presente estudo, Pereira (2009) verificou, utilizando adubação mineral e as leguminosas crotalária e feijão-de-porco no pré-plantio e em consórcio com a bananeira cv Pacovan, efeito pouco expressivo da adubação tanto orgânica (adubação verde) quanto mineral sob os componentes de produção e o atribuiu ao efeito residual proveniente dos restos culturais da bananeira incorporados ao solo em ciclos anteriores.

Quanto à produtividade e ao número de pencas da cv Prata Anã, Melo et al. (2010) utilizando doses de N e K similares a da testemunha do presente trabalho $\left(700 \mathrm{~kg} \mathrm{ha}^{-1}\right.$ de $\mathrm{N}$ e $400 \mathrm{~kg} \mathrm{ha}^{-1}$ de $\mathrm{K}_{2} \mathrm{O}$ ) conseguiram uma produtividade de 24,84 $\mathrm{Mg} \mathrm{ha}^{-1}$, e o valor estimado de 7,92 pencas cacho ${ }^{-1}$, inferiores a 29,34 $\mathrm{Mg} \mathrm{ha}^{-1}$ e 9 pencas cacho ${ }^{-1}$ alcançados neste estudo; mesmo assim, valores correspondentes a 9,0 pencas cacho $^{-1}$ foram verificados na mesma cultivar, por Leonel et al. (2004) e estão de acordo com o observado no tratamento testemunha. Para o número de frutos por cacho, Pereira et al. (2003) obtiveram, no primeiro ciclo da bananeira cv Prata-Anã no município de Lavras-MG, em média 97,52 frutos cacho ${ }^{-1}$, valor inferior aos obtidos no presente estudo com as plantas testemunha e com as consorciadas com leguminosas.

Tomando por base a produtividade da bananeira verifica-se que o manejo FC e CK correspondeu respectivamente a 81,8 e $77,6 \%$ da produtividade da bananeira obtida com a aplicação de $700 \mathrm{~kg}$ ha ano $^{-1}$ (testemunha) destacando a importância do uso de leguminosas para o suprimento do $\mathrm{N}$ na cultura da bananeira e dá indicativos da elevada perda de $\mathrm{N}$ fertilizante. Esta perda pode estar associada, em parte, ao elevado total de precipitação que pode ter causado a lixiviação de parte do $\mathrm{N}$ aplicado, fato que ficou evidenciado pela redução nos teores de $\mathrm{N}$ nos tratamentos com maiores lâminas totais de água. 
Quanto à duração do primeiro ciclo da bananeira (Tabela 2) verificou-se que as plantas testemunha necessitaram de 334 dias do plantio até a colheita dos frutos, valor que corresponde à redução de 40 dias no ciclo dessas plantas em comparação ao ciclo das bananeiras consorciadas com a vegetação espontânea. Nas bananeiras consorciadas com leguminosas o ciclo foi de 341 dias para o consócio $\mathrm{FC} \mathrm{e} 342$ dias para $\mathrm{CK}$, sendo a diferença de apenas 7 e 8 dias, respectivamente, em comparação com a testemunha.

A menor duração do ciclo das bananeiras da testemunha pode ser atribuída à melhor nutrição das plantas desse tratamento, particularmente a nitrogenada. Melo et al. (2010) observaram a antecipação de 103 dias na colheita no primeiro ciclo da bananeira Prata-Anã, quando utilizaram conjuntamente 1016 $\mathrm{kg} \mathrm{ha}^{-1}$ de $\mathrm{N}$ e $1200 \mathrm{~kg} \mathrm{ha}^{-1}$ de $\mathrm{K}_{2} \mathrm{O}$ e afirmaram que o ciclo dessa cultivar é prolongado em situações de deficiência de $\mathrm{Ne}$ K. A antecipação da colheita do primeiro ciclo da bananeira cv Nanica consorciada com leguminosas foi observada também por Espindola et al. (2006b). No presente estudo as bananeiras consorciadas com leguminosas também apresentaram redução do primeiro ciclo em comparação com as plantas consorciadas com vegetação espontânea; no entanto, o total de dias do plantio até a colheita foi inferior ao encontrado por Espindola et al. (2006b). É importante destacar que esses autores trabalharam com outra cultivar e as condições edafoclimáticas também eram diferentes das condições observadas no semiárido, onde foi realizado o presente estudo. Durações do primeiro ciclo semelhantes à observada neste trabalho, foram obtidas por Figueiredo et al. (2006) para a cultivar Prata anã e corresponderam a 365 dias. Com a cv Pacovan, Lima et al. (2005) relataram o total de 362 dias necessários do transplantio até a colheita.

\section{CONClusÕes}

1. O total de água aplicado no primeiro ciclo da bananeira cv Prata Anã na menor lâmina de irrigação somada a precipitação, garantiu produtividade similar à observada com a aplicação de maiores lâminas.

2. A utilização da cobertura morta de leguminosas no pré-plantio, exerceu influências positivas no crescimento, na nutrição nitrogenada e na produção da bananeira, substituindo parcialmente o $\mathrm{N}$ aplicado como fertilizante mineral.

3. $\mathrm{O}$ uso de leguminosas consorciadas com a bananeira representa uma alternativa adequada para o fornecimento de $\mathrm{N}$ à cultura da bananeira sobre tudo em empreendimentos agrícolas que fazem uso da produção orgânica.

\section{Agradecimentos}

À Universidade Federal do Ceará (UFC) pelo apoio logístico e de infraestrutura, ao Banco do Nordeste (BNB) pelo apoio financeiro à pesquisa e à Capes pela concessão da bolsa de estudo da primeira autora.

\section{Literatura Citada}

Bremer Neto, H.; Victoria Filho, R.; Mourão Filho, F. de A. A.; Menezes, G. M.; Canali, E. Estado nutricional e produção de laranjeira 'Pêra' em função da vegetação intercalar e cobertura morta. Pesquisa Agropecuária Brasileira, v.43, p.29-35, 2008.
Carvalho, M. A. C.; Athayde, M. L. F.; Soratto, R. P.; Alves, M. C.; Sá, M. E. Adubação verde e sistemas de manejo do solo na produtividade do algodoeiro. Pesquisa Agropecuária Brasileira, v.39, p.1205-1211, 2004.

Castro, C. M.; Alves, B. J. R.; Almeida, D. L.; Ribeiro, R. L. D. Adubação verde como fonte de nitrogênio para a cultura da berinjela em sistema orgânico. Pesquisa Agropecuária Brasileira, v.39, p.779-785, 2004.

Coelho, E. F.; Ledo, C. A. da S.; Silva, S. de O. Produtividade da bananeira 'Prata-Anã'e 'Grande Naine' no terceiro ciclo sob irrigação por microaspersão em tabuleiros costeiros da Bahia. Revista Brasileira de Fruticultura, v.28, p.435-438, 2006.

Costa, S. C.; Soares, A. A.; Sediyama, G. C.; Viana, T.V.A.; Moreira, F. V. O. Comportamento dos parâmetros indicativos de produção da bananeira Pacovan submetida a diferentes lâminas de irrigação e doses de potássio na Chapada do Apodi - Limoeiro do Norte-CE. Revista Caatinga, v.22, p.46-52, 2009.

EMBRAPA - Empresa Brasileira d e Pesquisa Agropecuária. Manual de métodos de análise de solos. 2.ed. Rio de Janeiro: Centro Nacional de Pesquisa de Solos, 1997. 212p.

Espindola, J. A. A.; Guerra, J. G. M.; Almeida, D. L.; Teixeira, M. G.; Urquiaga, S. Decomposição e liberação de nutrientes acumulados em leguminosas herbáceas perenes consorciadas com bananeira. Revista Brasileira de Ciência do Solo, v.30, p.321-328, 2006a.

Espindola, J. A. A.; Guerra, J. G. M.; Perin, A.; Teixeira, M. G.; Almeida, D. L.; Urquiaga, S.; Busquet, R.N.B. Bananeiras consorciadas com leguminosas herbáceas perenes utilizadas como coberturas vivas. Pesquisa Agropecuária Brasileira, v.41, p.415-420, 2006b.

FAO - Food and Agriculture Organization of the United Nations. FAOSTAT home. $<$ http://www.fao.org>. 12 Fev. 2012.

Fernandes, M. S. Nutrição mineral de plantas. 1.ed. Viçosa: SBCS, 2006. 432p.

Figueiredo, F. P.; Mantovani, E. C.; Soares, A. A.; Costa, L. C.; Ramos, M. M.; Oliveira, F. G. Produtividade e qualidade da banana prata anã, influenciada por lâminas de água, cultivada no Norte de Minas Gerais. Revista Brasileira de Engenharia Agrícola e Ambiental, v.10, p.798-803, 2006.

Kabaija, E.; Smith, O. B. The Effect of age of regrowth on content and release of manganese, iron, zinc and copper from four tropical forages incubated in sacco in rumen of sheep. Animal Feed Science and Technology, v.20, p.171176, 1988.

Kramberger, B.; Gselmana, A.; Janzekovica, M.; Kaligaricb, M.; Brackoa, B. Effects of cover crops on soil mineral nitrogen and on the yield and nitrogen content of maize. European Journal of Agronomy, v.31, p.103-109, 2009.

Leonel, S.; Gomes, E. M.; Pedroso, C. J. Desempenho agronômico de bananeiras micropropagadas em BotucatuSP. Revista Brasileira de Fruticultura, v.26, p.245-248, 2004.

Lima, M. B.; Silva, S. O.; Jesus, O. N.; Oliveira, W. S. J.; Garrido, M. S.; Azevedo, R. L. Avaliação de cultivares e híbridos de bananeira no Recôncavo Baiano. Ciência e Agrotecnologia, v.29, p.515-520, 2005. 
Malavolta, L. A.; Vitti, G. G.; Oliveira, S. A. Avaliação do estado nutricional das plantas: princípios e aplicações. 2. ed. Piracicaba: POTAFOS, 1997. 319p.

Melo, A. S. de; Sobral, L. S.; Fernandes, P. D.; Brito, M. E. B.; Viégas, P. R. A. Aspectos técnicos e econômicos da bananeira 'prata-anã' sob fertirrigação nos tabuleiros costeiros de Sergipe. Ciência e Agrotecnologia, v.34, p.564-571, 2010.

Pereira, L. V.; Silva, S. O.; Alves, J. E.; Silva, C. R. R. Avaliação de cultivares e híbridos de bananeira em LavrasMG. Ciência e Agrotecnologia, v.27, p.17-25, 2003.

Pereira, N. S. Utilização de leguminosas como fonte de nitrogênio para a cultura da bananeira. Fortaleza: UFC, 2009. 49p. Dissertação Mestrado

Perin, A.; Guerra, J. G. M.; Espindola, J. A. A.; Busquet, R. N. B. Desempenho de bananeiras consorciadas com leguminosas herbáceas perenes. Ciência e Agrotecnologia, v.33, p.15111517, 2009.

Prado, R. M. Nutrição de plantas.1.ed. São Paulo: UNESP, 2008. 407p.

Resende. G. M.; Alvarenga, M. A. R.; Yuri, J. E.; Souza, R. J. Doses de nitrogênio e molibdênio no rendimento e teor de micronutrientes em alface americana. Horticultura Brasileira, v.28, p.266-270, 2010.
Santos, V. P. dos; Fernandes, P. D.; Melo, A. S. de; Sobral, L. F.; Brito, M. E. B.; Dantas, D. de M.; Bonfim, L.V. Fertirrigação da bananeira cv. Prata-Anã com N e K em um argissolo vermelho-amarelo. Revista Brasileira de Fruticultura, v.31, p.567-573, 2009.

Silva, A. A.; Silva, P. R. F.; Suhre, E.; Argenta, G.; Strieder, M.; Rambo, L. Sistemas de coberturas de solo no inverno e seus efeitos no rendimento de grãos de milho em sucessão. Ciência Rural, v.37, p.928-935, 2007.

Silva, E. N. E.; Bezerra, F. M. L. Evapotranspiração e coeficientes de cultivo da bananeira no Vale do Curu, CE. Revista Ciência Agronômica, v.40, p.203-210, 2009.

Silva, J. A. A. da; Vitti, G. C.; Stuchi, E. S.; Sempionato, O. R. Reciclagem e incorporação de nutrientes ao solo pelo cultivo intercalar de adubos verdes em pomar de laranjeira 'Pêra'. Revista Brasileira de Fruticultura, v.24, p.225-230, 2002.

Spagnollo, E.; Bayer, C.; Wildner, L. P.; Ernani, P. R.; Albuquerque, J. A.; Proença, M. M. Leguminosas estivais intercalares como fonte de nitrogênio para o milho no sul do Brasil. Revista Brasileira de Ciência do Solo, v.26, p.417-423, 2002.

Zhu, A.; Zhang, J.; Zhao, B.; Cheng, Z.; Li, L. Water balance and nitrate leaching losses under intensive crop production with Ochric Aquic Cambosols in North China Plain. Environment International, v.31, p.904-912, 2005. 